\title{
Use of WhatsApp in Dental Education: a Scoping Review
}

\author{
Joice Catiane S. Martins ${ }^{1}$ (I) $\cdot$ Joana Beatriz de Lima ${ }^{1} \cdot$ Renata O. Cartaxo ${ }^{1}$ (i) $\cdot$ Pedro Henrique Sette-de-Souza ${ }^{1,2,3}$ (I)
}

Accepted: 2 February 2022 / Published online: 26 February 2022

(c) The Author(s) under exclusive licence to International Association of Medical Science Educators 2022

\begin{abstract}
Purpose/Objective This study aimed to perform a critical appraisal of WhatsApp use by undergraduate students in dental education.

Methods A PRISMA-Scoping Review was carried out to explain (i) how has WhatsApp been used as a learning tool in dental education? and (ii) how has Whats App been evaluated as a learning tool in dental education? Inclusion criteria are specified as the population (dental students), concept (use of WhatsApp), context (institutions/universities of dental education), and types of sources of evidence (peer-reviewed publication).

Results Nine studies published between 2016 and 2020 were included in this scoping review. Mostly had a cross-sectional design.

Conclusion WhatsApp is used in dental education to facilitate communication and improve learning through discussions via the app.
\end{abstract}

Keywords Communication skills $\cdot$ Dentistry $\cdot$ E-learning/Computers $\cdot$ WhatsApp $\cdot$ Social media

\section{Introduction}

Although it has undergone numerous changes in recent years, traditional education still has several characteristics that do not match contemporary standards. This teaching model is based mainly on the transmission of knowledge from teachers to students [1]. In this sense, the dialogue between teacherstudent, which is the basis of the learning process, becomes impaired. Moreover, teachers who use the traditional format limit their teaching methodologies to expository classes, annulling the possibilities of working on student autonomy to become the protagonists of the teaching-learning process [2].

Therefore, it is essential to work on students' interpretative autonomy to contribute to the formation of professionals capable of acting efficiently in the situations that arise

Pedro Henrique Sette-de-Souza

pedro.souza@upe.br

1 School of Dentistry, Universidade de Pernambuco, São Cristóvão, Arcoverde, Pernambuco, Brazil

2 Graduate Program in Health and Socioambiental Development, Universidade de Pernambuco, Garanhuns, Pernambuco, Brazil

3 Graduate Program in Dentistry, Universidade de Pernambuco, Pernambuco, Recife, Brazil in their daily work activities [2]. To this aim, technologies emerge as unavoidable tools for managing and supporting teaching and learning processes. In this process, these tools assume a relevant role, as they provide students with conditions to expand access to information, acquisition, and sharing of knowledge, promoting their autonomy, collaboration, participation, and interaction with the various learning spaces [3].

Then, technologies have been gaining space each day in the educational field due to their several advantages, besides the ease of access and acceptance of the new generation. Consequently, the teacher needs to make technologies a pedagogical work methodology [4]. In this sense, social media, which are interactive platforms that allow the creation and exchange of content generated by users, are an alternative. Moreover, there is a rapid growth of these platforms, and the complexities are decreasing every day, resulting in more user-friendly apps [5]. Among social networking apps for smartphones, WhatsApp has become the most accepted and conveniently used. Furthermore, its use has increased significantly since its launch in 2009 [6], with more than 2 billion users nowadays [7].

Regarding this issue, emerging technologies, including social media apps such as WhatsApp, are becoming more frequent in higher education, and this is also a reality for 
health sciences [8]. These apps in medical and dental education have proven to increase student participation, improve the feedback process, and improve communication between student and tutor [9]. WhatsApp is the social media app most popular among dental students due to its facility of keeping in touch with friends or family [10]. Thus, the integration of WhatsApp in educational courses allows its users a variety of resources, and therefore teachers and students are encouraged to use the apps in education due to its positive qualities and resources that increase understanding [11]. However, some limitations about empirical education research on this issue remain poorly reported.

Based on this, many studies indicate that social media, such as WhatsApp, can be used in education. Thus, this article aims to map and synthesize information about how WhatsApp has been used and evaluated as a learning tool in dental education.

\section{Methods}

\section{Protocol and Registration}

The study's protocol was drafted using a modified Preferred Reporting Items for Systematic Reviews and Meta-Analyses extension for Scoping Reviews-PRISMA-ScR [12] -and the model for scoping review proposed by Arksey and O'Malley [13]. The final protocol was registered with the Open Science Framework (RRID:SCR_003238) on 10 December 2020 (https://osf.io/tn3c4).

\section{Identifying the Research Questions}

To identify the research questions, the proposed questions by Coleman and O'Connor [14] were modified: (i) How has WhatsApp been used as a learning tool in dental education? (ii) How has WhatsApp been evaluated as a learning tool in dental education?

\section{Eligibility Criteria}

Studies were included since (i) it was a peer-reviewed publication (including case reports and letters); (ii) it aimed was related to the use of WhatsApp by dental students; and (iii) it was written in English, Portuguese, or Spanish. No year restriction was applied. We excluded publications with secondary data (e.g., reviews or book chapters) and letter to the editor. The eligibility criteria are in line with the Joanna Briggs Institute Reviewer's Manual [16], once the detailed inclusion criteria are specified as the population (dental students), concept (use of WhatsApp), context (institutions/universities of dental education), and types of sources of evidence (peerreviewed publication).

\section{Search Strategy and Information Sources}

The search strategy used the association of Boolean descriptors and operators, as follows: (WhatsApp OR "mobile message" OR "instant messages") AND (“dental education" OR "dental student" OR "dental undergraduate").

The following bibliographic databases were used: PUBMED, EMBASE, SCOPUS, ScienceDirect, Web of Science, and SciELO. The final search results of each database were exported and downloaded in CIW or RIS format. The files were imported into the online platform of Rayyan QCRI (RRID:SCR_017584), and duplicates were removed.

\section{Selection of Sources of Evidence}

For the selection of eligible studies, the Rayyan was used [17]. Based on the eligibility criteria, two reviewers (JCSM and JBL) independently evaluated the same titles, abstracts, and full text of all publications identified by the searches. The disagreements on study selection and data extraction were resolved by consensus and discussion with a third reviewer (PHSS), when needed. The intra- and interobserver kappa coefficients were performed using $70 \%$ of previous identified studies. The selection of sources was carried out until 27 November 2020.

\section{Data Charting Process}

Appropriate study data were condensed in tabulated form for each study. We analyzed the variables related to the authors' name, year of publication, place of development of the research, aims/question, study population/sample size (when applicable), methodology, intervention type (when applicable), concept, how outcomes are measured, and key findings that relate to the review question.

\section{Synthesis of Results}

After data tabulation, a narrative approach to summarizing and reporting the data was adopted. The results were presented and discussed according to our two research questions.

\section{Results}

\section{Summary of the Articles}

A total of 66 titles were retrieved using the search strategy. After duplicate removal, 44 unique studies were evaluated independently by reviewers through eligibility criteria (Fig. 1). The intraexaminer kappa coefficient was 0.90 (CI 0.58-1.00), and the interexaminer was 0.84 (CI 0.72-0.91). 


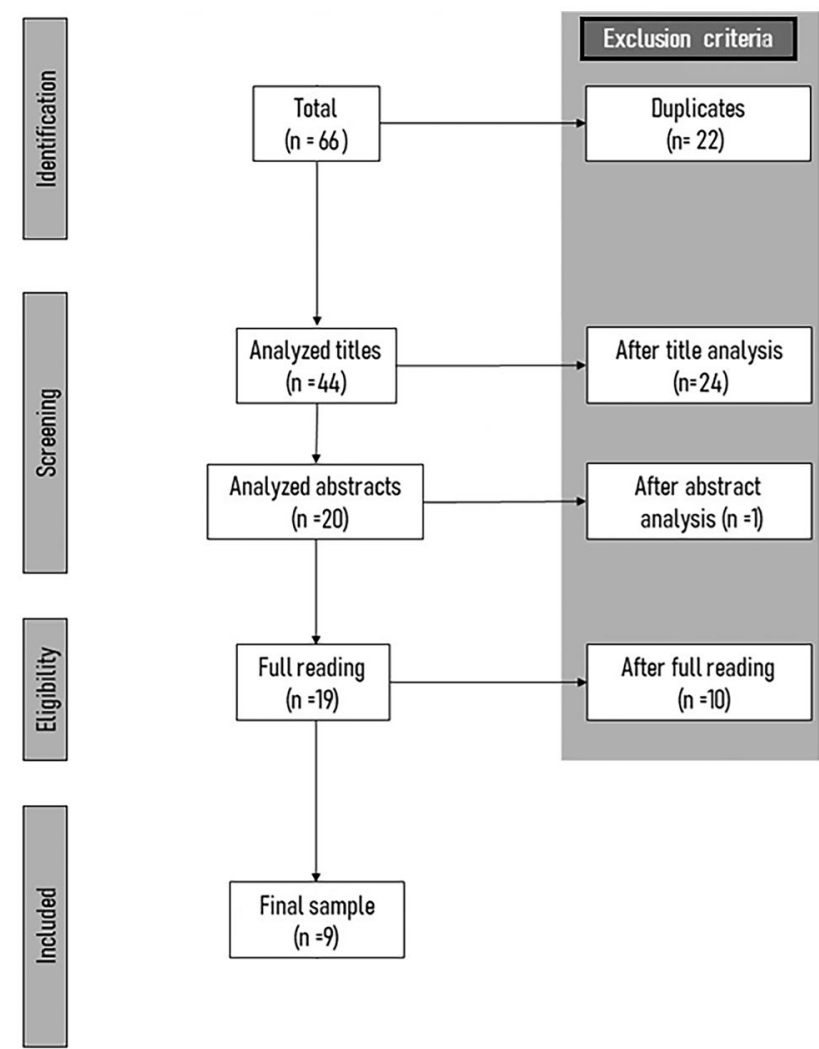

Fig. 1 Scheme of the selection of works

Finally, nine studies published between 2016 and 2020 were included in this scoping review (Table 1).

Seven (77.7\%) studies had a cross-sectional design, one $(11.1 \%)$ was a case report, and another $(11.1 \%)$ was a clinical trial. On the other hand, four (44.4\%) addressed WhatsApp's advantages and disadvantages and assessed whether students accepted it and whether it is a useful dental education tool. The other ones, three (33.3\%) evaluated the use of WhatsApp and other social media, one (11.1\%) compared the application with e-mail, and another (11.1\%) compared it with a Virtual Learning Environment (Moodle Platform). Most studies $(n=8 ; 88.9 \%)$ were carried out at a university, while one $(11.1 \%)$ was a multicenter study.

\section{How Has WhatsApp Been Used as a Learning Tool in Dental Education?}

Most studies $(n=4 ; 44.4 \%)$ evaluated the use of WhatsApp and other social media as facilitators of the teaching-learning process for exchanging messages and sending multimedia files. One study (11.1\%) compared WhatsApp with electronic e-mail in students' and teachers' communication, which considered the time for receiving and responding to messages sent in these tools. Another (11.1\%) compared WhatsApp with a Virtual Teaching Environment (Moodle Platform). The following items were compared: querying doubts, obtaining information, communicating with teachers, and communicating with colleagues.

One of the works (11.1\%) reported the use of the application as a means of communication to promote discussions between the teacher and the students; two others (22.2\%) showed that it can be used to share files and information relevant to dental education and that it can be useful to help make clinical decisions.

\section{How Has WhatsApp Been Evaluated as a Learning Tool in Dental Education?}

\section{Technical/Logistical Aspects of the Medium}

The selected articles presented information on the technical/ logistical aspects of WhatsApp. Among the advantages mentioned, the main one was speed. This ability to send instant messages makes it possible to clarify doubts quickly. The possibility of exchanging information and using multimedia resources were also benefits related to the application.

Concerning other messaging tools, such as e-mail, WhatsApp could verify that it has been delivered and read. The ability to send a group message at once was an advantage and a factor contributing to a large amount of this information not being relevant to specific individuals in the group. The technical disadvantages mentioned were technology limitation for cell phones, dependence on the internet connection, and vulnerabilities in professional secrecy and information without details.

\section{Learner/Learning Activity During WhatsApp Discussions}

Seven studies showed the content covered with the use of the application. The resource for sending multimedia files was the most used to promote discussions and learning. These included videos, images, and audio. Other positive uses were ease of communication with teachers and monitors in administrative and clinical matters and access to didactic material.

One of the works motivated learning mainly through textual involvement, with the elaboration of questions and problems. Through discussions on essential immunology/ microbiology topics directly related to SARS-CoV-2, the professor stimulated through news, social media posts, and serological tests while safeguarding ethical principles.

\section{Educational Outcomes of the Medium}

Most studies ( $n=6 ; 66.6 \%)$ evaluated the application's use through questionnaires answered by students who use this instrument. These studies showed that this resource allows students to obtain more information on different subjects, makes education more engaging, and improves the capacity for creativity and innovation, and assists clinical decisions. 


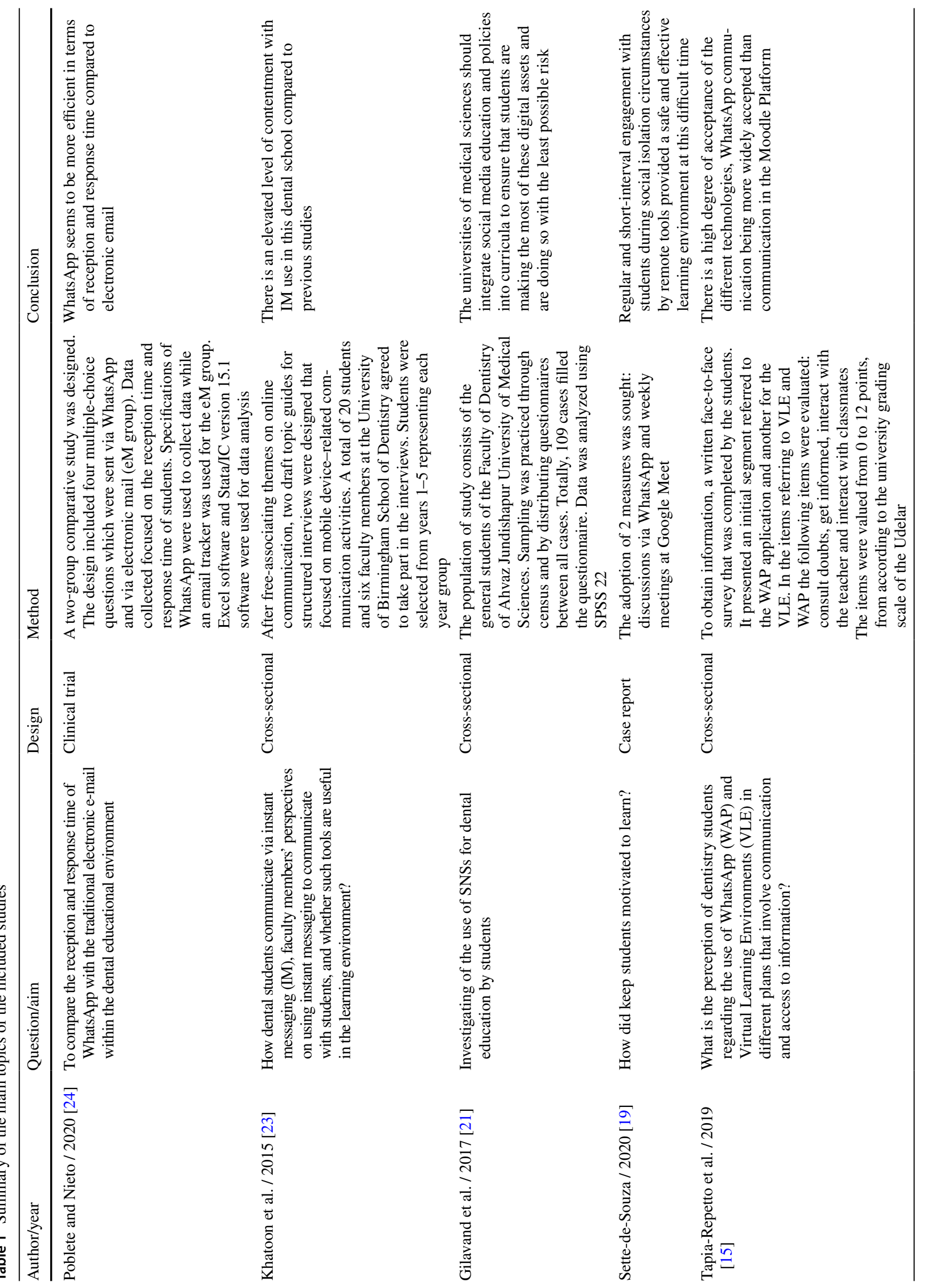




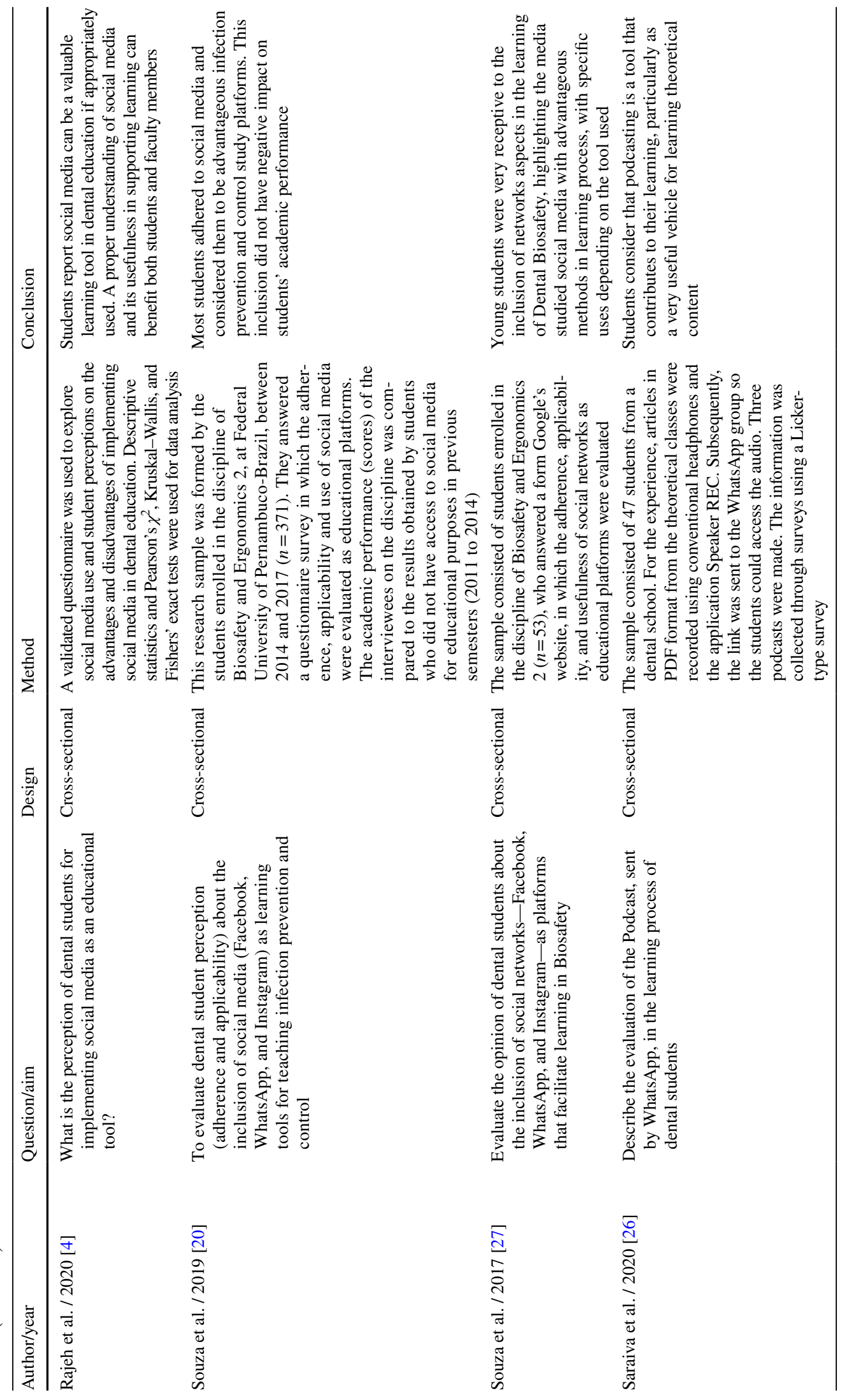


One of the studies used the file-sharing feature, in which podcasts were sent with issues related to dentistry and concluded that the application is an excellent alternative to be used for this purpose and is useful for dental education. In another study, WhatsApp was also considered a useful tool to communicate and motivate students. In this study, discussions were proposed using the application, which resulted in greater student involvement, who voluntarily shared the excitement of learning and recommended other activities.

Only one study compared the result obtained with WhatsApp with the result of a group that did not use the application. However, the comparison of test scores obtained by students enrolled in the course before and after social media inclusion does not indicate a statistically significant difference between the questions. Another study compared the students' assessments for WhatsApp and the Moodle Platform, and the results showed that WhatsApp obtained a higher score on all items evaluated.

Another study cited the main disadvantages, including study distraction, increased dependency potential, more time spent, and concerns about not having direct contact with instructors (Rajeh et al., [4]. Nevertheless, it recognizes that social media can be a valuable learning tool in dental education if appropriately used.

\section{Discussion}

This review presents several aspects of the use of WhatsApp by undergraduates in dental education. Most studies were cross-sectional and used questionnaires pre-defined by pilot studies or were pilot studies. All the studies were related to the use of the application in the university environment. The papers that addressed educational issues with this tool showed that WhatsApp is a useful tool for the teaching-learning process in dentistry.

Communication and the tools to develop them are essential in education. Especially in recent years, with the arrival of new technologies, the challenge arises to transform them into tools that collaborate with the teaching-learning process. In this sense, there is the agreement that these technologies are instruments capable of enhancing higher education [15].

The utility of using the WhatsApp application in daily clinical decisions was studied [18]. It was possible to verify that the application was useful for $85.71 \%$ of the interviewees. Regarding the utility of the application for studying, the results showed that this was useful for $88.10 \%$ of the interviewees. Thus, WhatsApp was considered a useful tool for accessing information and supporting the teaching-learning process and clinical decisions.

Another paper considered the WhatsApp a useful tool to communicate and motivate students, especially during times of social isolation [19]. In this study, discussions were proposed using the app, which resulted in greater student engagement, who voluntarily shared learning excitement, recommending additional gatherings and other activities. On the other hand, neither all identified studies reported a plan to use WhatsApp or if all students contributed to the exchange of messages or only the educator. We believe this knowledge gap should be better explained in further studies.

WhatsApp is one of the most used social media by dentistry students and has several benefits when used for dental education [4, 20, 21]. The main advantages observed in these studies include the following: faster and easier communication [22], helping to obtain more information on different subjects, making education more engaging, providing a better chance of accessing new resources, improving the capacity for creativity and innovation, and improving research skills. In contrast, the predominant disadvantages were a distraction from studying, increased addictive potential, increased time spent, and concerns over no direct contact with the instructors [4].

Besides that, the effectiveness of WhatsApp concerning electronic e-mail regarding the response time of messages was observed [24]. WhatsApp has several benefits to be used as a means of communication between students and teachers, such as being more instant and allowing confirmation that messages were delivered and read since this is not possible when using e-mail [23]. Moreover, WhatsApp was defined as a useful tool for students' communication and obtained a superior evaluation than Virtual Learning EnvironmentVLE [15].

The main strength of this review is the use of a transparent and reproducible procedure. Our protocol presents a detailed description of the population, concept, context, data sources, search strategy, data extraction, and analysis. However, we limited the review to only studies focused on undergraduate dental education. We strongly believe that our review will help professors who plan to use WhatsApp in dental education. In this scoping review, we will not assess the impact of simulation intervention nor the quality of the identified interventions [4, 11, 14, 16, 24-27].

\section{Conclusion}

Therefore, most of the selected studies have shown that WhatsApp is a useful tool to be used as an ally of pedagogical activities, both in the exposure of information and in providing collaborative and interactive spaces between learners, and is more efficient than other applications. Thus, the referred application presents itself as a simple digital communication tool between teachers and students and can strengthen the bridge between education and technology. 
Funding The Coordenação de Aperfeiçoamento de Pessoal de Nível Superior - Brasil (CAPES, Finance Code 001) financed this study in part.

Availability of Data and Material http://scopus.com/; http://pubmed.ncbi. nlm.nih.gov/; https://www.embase.com/; http://isiwebofknowledge.com

\section{Declarations}

Conflict of Interest The authors declare no competing interests.

\section{References}

1. Lacerda FCB, Santos LM. Integralidade na formação do ensino superior: metodologias ativas de aprendizagem. Avaliação. 2018;23(3):61127. https://doi.org/10.1590/S1414-40772018000300003.

2. Seibel W. A importância do uso de metodologias ativas no ensino superior: superando os limites do ensino tradicional. Revista Científica da FAESA. 2020;16(2):46-53. https://doi.org/10.5008/ 1809.7367.176.

3. Pinto M, Leite C. Digital technologies in successful academic itineraries of higher education non-traditional students. Educ Pesqui. 2020;46: e216818. https://doi.org/10.1590/S1678-4634202046216818.

4. Rajeh MT, Sembawa SN, Nassar AA, Al Hebshi SA, Aboalshamat KT, Badri MK. Social media as a learning tool: dental students' perspectives. J Dent Educ. 2020;85(4):513-20. https://doi.org/10. 1002/jdd.12478.

5. Latif MZ, Hussain I, Saeed R, Qureshi MA, Maqsood U. Use of smart phones and social media in medical education: trends, advantages, challenges and barriers. Acta informatica medica : AIM : journal of the Society for Medical Informatics of Bosnia \& Herzegovina : casopis Drustva za medicinsku informatiku BiH. 2019;27(2):133-8. https://doi.org/10.5455/aim.2019.27.133-138.

6. Grover S, Garg B, Sood N. Introduction of case-based learning aided by WhatsApp messenger in pathology teaching for medical students. J Postgrad Med. 2020;66(1):17-22. https://doi.org/10. 4103/jpgm.JPGM_2_19.

7. Dean, B. WhatsApp 2021 user statistics: how many people use WhatsApp? 2021. https://backlinko.com/whatsapp-users. Accessed 20 Dec 2021.

8. Willemse JJ. Undergraduate nurses reflections on WhatsApp use in improving primary health care education. Curationis. 2015;38(2):1512. https://doi.org/10.4102/curationis.v38i2.1512.

9. Raiman L, Antbring R, Mahmood A. WhatsApp messenger as a tool to supplement medical education for medical students on clinical attachment. BMC Med Educ. 2017;17(1):7. https://doi. org/10.1186/s12909-017-0855-x.

10. Uma E, Nieminen P, Mani SA, John J, Haapanen E, Laitala ML, Lappalainen OP, Varghase E, Arora A, Kaur K. Social media usage among dental undergraduate students-a comparative study. Healthcare (Basel). 2021;9(11):1408. https://doi.org/10.3390/ healthcare9111408.

11. Alshaibani MH, Qusti ES. The role of smartphone app "WhatsApp" on achievement motivation and social intelligence among female undergraduate students. Perspect Psychiatr Care. 2020;57(2):597_ 603. https://doi.org/10.1111/ppc.12582.

12. Tricco AC, Lillie E, Zarin W, O'Brien KK, Colquhoun H, Levac D, Moher D, Peters M, Horsley T, Weeks L, Hempel S, Akl EA, Chang C, McGowan J, Stewart L, Hartling L, Aldcroft A, Wilson MG, Garritty C, Lewin S, Straus SE. PRISMA Extension for Scoping Reviews (PRISMA-ScR): checklist and explanation. Ann Intern Med. 2018;169(7):467-73. https://doi.org/10.7326/ M18-0850.

13. Arksey H, O'Malley L. Scoping studies: towards a methodological framework. Int J Soc Res Methodol. 2005;8(1):19-32. https://doi. org/10.1080/1364557032000119616.

14. Coleman E, O'Connor E. The role of WhatsApp ${ }^{\circledR}$ in medical education; a scoping review and instructional design model. BMC Med Educ. 2019;19(1):279. https://doi.org/10.1186/ s12909-019-1706-8.

15. Tapia-Repetto G, Gutierrez C, Tremillo-Maldonado O. Nuevas tecnologías en educación superior. Estudio de percepción en estudiantes acerca del uso de WhatsApp y Entornos Virtuales de Aprendizaje (Plataforma Moodle). Odontoestomatología. 2019;21(33):37-43. https://doi.org/10.22592/ode2019n33a5.

16. Peters MDJ, Godfrey C, McInerney P, Munn Z, Tricco AC, Khalil H. Chapter 11: Scoping reviews. In: E. Aromataris \& Z. Munn (Eds). JBI Manual for Evidence Synthesis. JBI. 2020.

17. Ouzzani M, Hammady H, Fedorowicz Z, Elmagarmid A. Rayyan-a web and mobile app for systematic reviews. Syst Rev. 2016;5(1):210. https://doi.org/10.1186/s13643-016-0384-4.

18. Tavares ARPG, Sobral APT, Motta LJ. Uso de la aplicación WhatsApp por estudiantes de Odontología de Sao Paulo, Brasil. Revista Cubana de Información en Ciencias de la Salud. 2016;27(4):503-14.

19. Sette-de-Souza PH. Motivating learners in pandemic period through WhatsApp and Google Meet. J Dent Educ. 2020. https:// doi.org/10.1002/jdd.12352.

20. Souza FB, Kim JW, Carvalho EJ, Jamelli SR, Melo MM. Social media for teaching infection prevention and control in dentistry: survey of students perception and comparative study of academic performance. 2019;13(4):JC01-JC05. https://doi.org/10.7860/ JCDR/2019/40206/12750.

21. Gilavand A, Shooriabi M, Mansoori B. Investigating the use of social networking sites for dental education by students: a regional survey. Ann Dent. 2017;5(3).

22. Arani, AJ. An innovative media platform-supported blended methodology in English for dental purposes program. International Journal of Emerging Technologies in Learning (iJET), 2016;12(03):98-109. https://doi.org/10.3991/ijet.v12i03.6441

23. Khatoon $\mathrm{B}$, Hill KB, Walmsley AD. Instant messaging in dental education. J Dent Educ. 2015;79(12):1471-8.

24. Poblete P, Nieto E. Does time matter? WhatsApp vs electronic mail for dental education. A pilot study. Eur J Dent Educ. 2020;24(1):121-125. https://doi.org/10.1111/eje.12475.

25. Asgari AJ. An innovative media platform-supported blended methodology in English for dental purposes program. Int J Emerg Technol Learn. 2017;12(03):98-109. https://doi.org/10.3991/ijet. v12i03.6441.

26. Saraiva M, Orejuela F, Fukuhara M. Valoración del Podcasting en la enseñanza clínica en el área de odontología restauradora. Revista Estomatológica Herediana. 2020;30(2):108-112. https:// doi.org/10.20453/reh.v30i2.3762.

27. Souza FB, Lopes MGQ, Lima Filho RM. Redes sociales en el aprendizaje de la odontología: opinión de los estudiantes de una universidad brasileña. Rev Cubana Estomatol. 2017;54(2):1-11.

Publisher's Note Springer Nature remains neutral with regard to jurisdictional claims in published maps and institutional affiliations. 